\title{
Faithful Expression of Multiple Proteins via 2A-Peptide Self- Processing: A Versatile and Reliable Method for Manipulating Brain Circuits
}

\author{
Wannan Tang ( 唐宛男), ${ }^{1}$ Ingrid Ehrlich, ${ }^{2}$ Steffen B. E. Wolff, ${ }^{2}$ Ann-Marie Michalski, ${ }^{1,3}$ Stefan Wölfl, ${ }^{3}$ \\ Mazahir T. Hasan, ${ }^{1}$ Andreas Lüthi, ${ }^{2}$ and Rolf Sprengel ${ }^{1}$ \\ ${ }^{1}$ Department of Molecular Neurobiology, Max Planck Institute for Medical Research, D-69120 Heidelberg, Germany, ${ }^{2}$ Friedrich Miescher Institute for \\ Biomedical Research, CH-4058 Basel, Switzerland, and ${ }^{3}$ Institute for Pharmacy and Molecular Biotechnology, University of Heidelberg, D-69120 \\ Heidelberg, Germany
}

\section{Introduction}

A method allowing for efficient and quantitative coexpression of multiple heterologous proteins in neurons in vivo would be highly valuable for many applications in neuroscience. To date, different approaches, such as internal ribosomal entry site (IRES) elements (Douin et al., 2004), bidirectional or double promoters (Baron et al., 1995), or coinfection with multiple viral vectors (Mastakov et al., 2002), are commonly used. These strategies, however, mostly suffer from the fundamental problem that coexpression of the heterologous proteins is unreliable and far from quantitative. In the case of IRES-mediated coexpression, for example, the upstream

Received Jan. 22, 2009; revised June 5, 2009; accepted June 8, 2009.

This work was supported by the Volkswagen-Foundation (AZ:I/80704), the Swiss National Science Foundation, the Austrian Science Fund, the German Research Foundation (SFB636/A4 and SP602/2-1 to R.S.), and the Novartis Research Foundation. Dox treatment and $\mathrm{rAAV}$ injection were performed under the license of Regierungspräsidium Karlsruhe 359815.82-A49/06 and 35-9815.81-A56/05. We thank Prof. Peter H. Seeburg for support and discussion. We thank Annette Herold, Sabine Grünwald, and Dr. Günter Giese for technical help. We also thank Daniela Gerosa-Erni and Dr. Thomas Oertner for providing hippocampal slice cultures, Prof. Wolfgang Hillen for providing TTA antibody, and Dr. Karl Deisseroth for providing Channelrhodopsin and Halorhodopsin plasmids.

Correspondence should be addressed to Rolf Sprengel, Department of Molecular Neurobiology, Max Planck Institute for Medical Research, Jahnstrasse 29, D-69120 Heidelberg, Germany. E-mail: rolf. sprengel@mpimf-heidelberg.mpg.de.

I. Ehrlich's present address: Hertie Institute for Clinical Brain Research, Paul-Ehrlich-Strasse 15-17, D-72076 Tübingen, Germany.

D01:10.1523/JNEUROSCI.0359-09.2009

Copyright $\odot$ 2009 Society for Neuroscience $\quad$ 0270-6474/09/298621-09\$15.00/0 elements in these bicistronic mRNA open reading frames (ORFs) are more strongly transcribed than the IRES-controlled downstream protein (Hennecke et al., 2001).

An alternative and more promising approach involves the use of self-processing viral peptide bridges. So-called $2 \mathrm{~A}$ or $2 \mathrm{~A}$ like peptide sequences separate different protein coding sequences in a single ORF transcription unit of Picornaviridae (Ryan et al., 1991). The 2A peptide sequences from different members of the picornavirus family share a highly conserved motif of only 18 aa, mediating the cleavage between the C-terminal glycine and the $\mathrm{N}$-terminal proline of the downstream $2 \mathrm{~B}$ sequence (Ryan et al., 1991). Initially, the 2A peptide cleavage was thought to be mediated by an autoproteolytic event (Ryan et al., 1991), and 2A peptides were called "self-cleaving peptides." Ultimately, a ribosomal-skip mechanism was proposed, and 2A and 2A-like sequences are now referred to as CHYSELs (cis-acting hydrolase elements) rather than selfcleaving peptides (Donnelly et al., 2001). Linking proteins with $2 \mathrm{~A}$ or $2 \mathrm{~A}$-like peptide sequences results in cellular expression of multiple, discrete proteins (in essentially equimolar quantities) derived from a single ORF (de Felipe et al., 2006).

The 2A peptide-mediated cleavage has previously been shown to result in coexpression of functional heterologous pro- teins in cell lines (Lengler et al., 2005; de Felipe et al., 2006), embryonic stem cells (Hasegawa et al., 2007), and neurons (Furler et al., 2001). In some cases, however, C-terminal $2 \mathrm{~A}$ peptide sequences resulted in impaired protein function (Lengler et al., 2005; Hasegawa et al., 2007). Surprisingly, the potential of this system has not been exploited in cellular and systems neuroscience. It has not been addressed whether $2 \mathrm{~A}$ peptide-mediated coexpression of heterologous proteins is quantitative in neurons and expression levels of fluorescent reporters would be high enough for in vivo electrophysiological and imaging applications. Another important issue is to ensure that $2 \mathrm{~A}$ peptide transcripts leave neuronal viability and function intact. Furthermore, it was unclear whether, in neurons, this technology could be extended to coexpress more than two proteins, including secreted and membrane proteins, which are critical players for understanding neural circuit function.

To address these questions, we analyzed the efficiency of coexpression of various proteins in neurons in vitro and in vivo, using a slightly modified Thosea asigna virus $2 \mathrm{~A}$ peptide bridge (de Felipe et al., 2006) containing a short C-terminal linker sequence composed of four amino acid residues. With this approach, we demonstrate efficient and reliable functional coexpression of multiple cytosolic, 
secreted and membrane proteins in neurons in vivo. We show that viral coexpression of the codon-improved Cre recombinase (iCre) (Shimshek et al., 2002) or an improved tetracycline-controlled transactivator (itTA) (Krestel et al., 2004) with fluorescent proteins (FPs) is compatible with in vitro and in vivo electrophysiological and imaging approaches, and can be combined with inducible genetic mouse models to enable targeted manipulation of faithfully labeled neuronal subgroups. Furthermore, by using two 2A sequences, three proteins can be simultaneously expressed under the control of a single promoter. In this last approach, we show that coexpression of a fluorescent reporter and two light-activated membrane proteins Channelrhodopsin2 (ChR) (Gradinaru et al., 2007) and Halorhodopsin (NpHR) (Gradinaru et al., 2008) may greatly simplify gene delivery for reliable bidirectional optical control of neuronal activity.

\section{Materials and Methods}

\section{Plasmid constructs}

The Thosea asigna virus $2 \mathrm{~A}$ peptide coding sequence together with $\mathrm{N}$-terminal CTC and C-terminal GCACCGGGATCCACC flanking sequences was synthesized and subcloned between BamHI and AgeI sites of plasmid pAAV6P-SEWB (Shevtsova et al., 2005). The iCre gene sequence (Shimshek et al., 2002) was cloned between the synapsin promoter and the $2 \mathrm{~A}$ peptide sequence to generate pAAV-SyniCre2A-EGFP. The pAAV-CMV-iCre2AEGFP was constructed by substituting of the CMV promoter for the synapsin promoter in construct pAAV-Syn-iCre2A-EGFP. The Venus sequence was inserted as PCR product by $5^{\prime}$-blunt end $3^{\prime}$-BsrGI ligation into pAAVSyn-iCre2A-EGFP vector in place of EGFP. The itTA (Krestel et al., 2004) and Kusabira Orange (KO) (Karasawa et al., 2004) gene sequences were generated by PCR and were used to replace iCre and Venus sequences in pAAVSyn-iCre2A-Venus, respectively. The iCre sequence was replaced by human Noggin PCR fragment to generate pAAV-Syn-Noggin2AVenus. The ChR (H134R) (Chlamydomonas reinhardtii Channelrhodopsin2) (Gradinaru et al., 2007) and tDimer sequences (Campbell et al., 2002) were generated by PCR to replace iCre and Venus, respectively, in pAAV-SyniCre2A-Venus to construct plasmid pAAVSyn-ChR2A-tDimer. For construction of pAAV-Syn-NpHR2A-Venus, the eNpHR (enhanced Natronomonas pharaonis Halorhodopsin) (Gradinaru et al., 2008) sequence was generated by PCR and replaced iCre in pAAV-SyniCre2A-Venus. The triple expression vector pAAV-Syn-ChR2A-NpHR2A-Venus was constructed by generation of NpHR and $2 \mathrm{~A}-\mathrm{Venus}$ sequences by $\mathrm{PCR}$ and successive insertion into pAAV-Syn-ChR2A-tDimer. All ChR and $\mathrm{NpHR}$ containing expression cassettes were shuttled into pAAV-CAG-shuttle (Applied Vi- romics). For construction of plasmid pHDiCre2A-Venus, the iCre2A-Venus fragment was isolated from plasmid pAAV-Syn-iCre2AVenus with EcoRI and BsrGI and subcloned between BglII and XhoI in plasmid pHD-iCre (Shimshek et al., 2002) by $5^{\prime}$ - and $3^{\prime}$ - blunt ligation to replace iCre sequence. All plasmids were sequenced after cloning.

\section{Transfection of cultured cells and staining assays}

Primary hippocampal neuron culture transfection was done with Lipofectamine 2000 (Invitrogen) at day 5 in vitro (DIV 5) as described previously (Dalby et al., 2004). HEK293 cells were transfected (Shimshek et al., 2002) with pAAV-CMV-iCre2A-EGFP. Other plasmids (pHD-iCre2A-Venus and pHD-iCre) were separately cotransfected with control plasmid (600 ng/well) pHD-AP into CV1/lacZ indicator cells in a 24-well plate (Shimshek et al., 2002). Activities of $\beta$-galactosidase and alkaline phosphatase were detected by X-Gal and Fast Red (Roche) stainings $48 \mathrm{~h}$ after transfection. The Cre-activity was evaluated by the ratio of blue to red cells, which reflects the fraction of cells with Cre-activity among the total number of transfected cells.

\section{Preparation and delivery of recombinant adeno-associated viruses}

Recombinant adeno-associated viruses (rAAVs) serotype 1 and 2 were generated and purified by iodixanol gradients as described before (Zolotukhin et al., 1999; Zhu et al., 2007). Since all viral constructs express FPs, titers were determined by infection of hippocampal primary neuron cultures. For this dissociated hippocampal neurons (Brewer et al., 1993) of E18 rats were plated at a density of $5 \times 10^{4}$ cells per well in 24-well plates coated with poly-Llysine (Sigma). Neurons were infected with rAAVs at DIV 4 with $0.1 \mu \mathrm{l}$ of virus. Two weeks later, fluorescent cells were counted to calculate the infectious titer, and rAAV preparations showing a titer of $10^{7}-10^{8}$ infectious particles $/ \mathrm{ml}$ were stored at $-70^{\circ} \mathrm{C}$ and used for further experiments. For the amygdala infection, purified rAAVs (serotype 7) were obtained from Penn Vector Core (titers: rAAV-SynChR-2A-tDimer, $5.36 \times 10^{12}$ genome copies/ $\mathrm{ml}$; rAAV-Syn-ChR-2A-NpHR-2A-Venus, $2.61 \times 10^{12}$ genome copies $/ \mathrm{ml}$ ). In the dissociated primary hippocampal neuron cultures, the expression of rAAV-transduced proteins was evaluated $10 \mathrm{~d}$ postinfection (DPI 10, with $0.5 \times 10^{4}-10^{5}$ infectious particles per well of a 24-well plate) by Western blots or immunohistochemistry. For in vivo expression, viruses were delivered into the brains of deeply anesthetized (ketamine/xylazine mix or isoflurane) 5- to 6-week-old mice by stereotactic injections as described in detail (Cetin et al., 2006). Stereotactic coordinates relative to bregma were as follows: anteroposterior (AP) $-2.1 \mathrm{~mm}$, lateral (Lat) $\pm 1.6 \mathrm{~mm}$, depth $0.3-1.6 \mathrm{~mm}$, for hippocampus and cortex, and AP $-1.7 \mathrm{~mm}$, Lat $\pm 3.3 \mathrm{~mm}$, depth $4.4 \mathrm{~mm}$ for amygdala. During each injection, $0.3 \mu$ l of purified rAAVs $\left(1.0 \times 10^{7}-10^{8}\right.$ infectious particles/ml for hippocampus and cortex infection; $2-5 \times 10^{12}$ genome copies/ $\mathrm{ml}$ for amygdala infection) was delivered by stereotactic injection. All procedures were performed according to the guidelines of the local animal use and care committees.

\section{Protein extraction and Western}

\section{blot analysis}

Transfected HEK293 cells and cultured primary hippocampal neurons were harvested with lysis buffer (50 mm Tris- $\mathrm{HCl}, \mathrm{pH} 7.6 ; 5$ $\mathrm{mm} \mathrm{MgCl}_{2} ; 130 \mathrm{~mm} \mathrm{NaCl} ; 10 \mathrm{~mm} \mathrm{KCl} ; 1 \%$ Triton X-100; $5 \%$ glycerin) 48 and $24 \mathrm{~h}$ after transfection, respectively, while infected primary hippocampal neurons were harvested $10 \mathrm{~d}$ after virus application. Brain tissue (cortex and hippocampus) was collected 2 weeks after virus infection and homogenized in ice-cold buffer (25 mM HEPES, pH 7.4) containing a protease inhibitor cocktail (Complete; Roche). From rAAV-infected neuron cultures, $10 \mu \mathrm{g}$ of total cell lysate and $20 \mu \mathrm{l}$ of culture medium were separated by SDS-PAGE (10\% separating and $4 \%$ stacking gels) and transferred to nitrocellulose membranes. Western blots were probed with polyclonal rabbit anti-Cre (1:8000, Covance), monoclonal mouse anti-GFP (1:10,000, Clontech), polyclonal rabbit antitTA $(1: 10,000$, provided by Prof. Dr. Wolfgang Hillen, Institute of Biology, FriedrichAlexander University, Erlangen, Germany), monoclonal rat anti-Noggin (1:1000, R\&D Systems), and polyclonal rabbit anti-DsRed (1: 1000, Clontech) antibodies. Horseradish peroxidase-linked anti-rabbit, anti-mouse, or anti-rat was used as secondary antibody (1:15,000, Vector Laboratories), and blots were visualized by enhanced chemiluminescence (ECL kit, GE Healthcare). Quantification of Western blots was done using Image (NIH).

\section{Immunohistochemistry}

Cultured primary hippocampal neurons at DPI 10 or brains from virus-injected mice at DPI 14 were fixed with $4 \%$ paraformaldehyde/ PBS, and $70 \mu \mathrm{m}$ coronal sections were obtained from the brains. Immunostaining was performed with polyclonal rabbit anti-Cre primary antibody (1:3000, Covance) and Cy3coupled anti-rabbit secondary antibody (1:200, Jackson ImmunoResearch). Activity of $\beta$-gal in brain slices of Rosa26R mice (Soriano, 1999) was visualized by X-Gal staining (Shimshek et al., 2002).

\section{Slice preparation and transfection of} slice cultures

Standard procedures were used to prepare acute, 300- $\mu \mathrm{m}$-thick brain slices (Bissière et al., 2003). Hippocampal slices were cut from 6 - to 7-week-old mice infected with rAAVs for 2-3 weeks, and amygdala slices were prepared from 8- to 10-week-old mice infected with rAAVs for 4-6 weeks. Hippocampal slice cultures were prepared from 5- to 7-d-old rat pups as previously described (Stoppini et al., 1991) and maintained in culture for 1-2 weeks. Plasmid DNA was prepared and biolistic transfection 
A

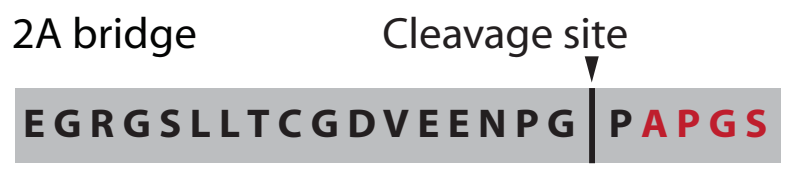

| rAAV-Syn-iCre2A-Venus
B

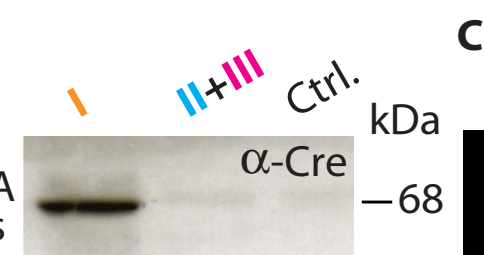

C

\begin{tabular}{|c|c||c|c|}
\hline Syn P & iCre & 2A & Venus \\
\hline
\end{tabular}

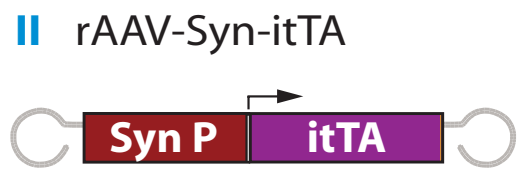

\section{III rAAV-Ptetbi-iCre-Venus}
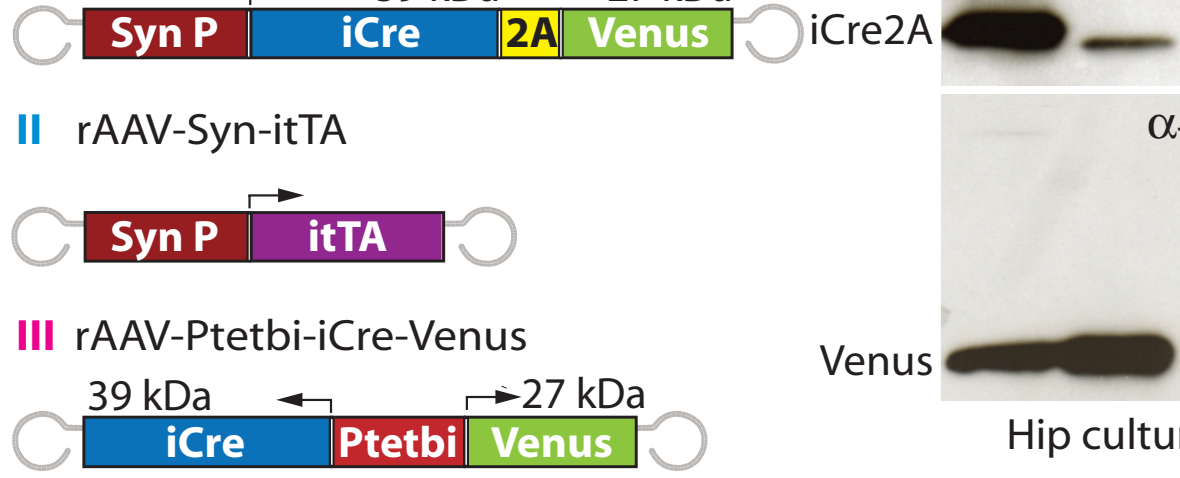

Venus

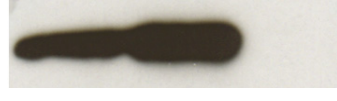

Hip culture

$\alpha$-GFP - 68

$-27$
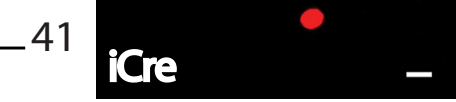

Figure 1. Reliable coexpression of heterologous proteins using $2 A$ peptide bridges in cultured neurons. $A$, Top, Amino acid residues of $2 A$ peptide from Thosea asigna virus. The cleavage site is indicated by the arrow. Amino acid residues in red were added to keep the C-terminal environment constant between different constructs. Bottom, Diagram of rAAV vector constructs. $\boldsymbol{B}$, $2 \mathrm{~A}$-mediated self-processing in primary hippocampal neuron cultures. Western blots of protein extracts from rAAV-infected hippocampal neurons at DPI 10. The 40.8 kDa iCre2A fusion protein and the $27.3 \mathrm{kDa}$ Venus were detected, and to a very small extent, the $68.1 \mathrm{kDa}$ precursor full-length protein. I, Neurons infected with rAAV-Syn-iCre2A-Venus. II+III, Neurons coinfected with the activator virus rAAV-Syn-tTA and rAAV-Ptetbi-iCre-Venus. Ctrl, Noninfected neurons. C, Confocal images of primary hippocampal neurons infected with rAAV-Syn-iCre2A-Venus at DPI 10. Neurons coexpress cleaved and freely diffusible Venus (green) and nuclear restricted iCre (red, visualized with Cy3-coupled antibody), indicating that the $2 \mathrm{~A}$ fusion construct was cleaved successfully in situ. Scale bars, $10 \mu \mathrm{m}$.

using a Gene Gun (Bio-Rad) was performed as described previously (Ehrlich and Malinow, 2004). Expression was allowed for 7-10 d before recording.

\section{Whole-cell recordings}

Neurons were visualized using infrared and fluorescence microscopy. The ACSF contained $124 \mathrm{~mm} \mathrm{NaCl}, 2.7 \mathrm{~mm} \mathrm{CaCl}_{2}, 1.3 \mathrm{~mm} \mathrm{MgCl}_{2}$, $2.7 \mathrm{~mm} \mathrm{KCl}, 26 \mathrm{~mm} \mathrm{NaHCO}_{3}$, and $0.4 \mathrm{~mm}$ $\mathrm{NaH}_{2} \mathrm{PO}_{4}$. Whole-cell recordings were obtained from neighboring control and infected or transfected pyramidal neurons in hippocampus or principal neurons in the basolateral amygdala. Patch electrodes (5-6 M $\Omega$ ) were pulled from borosilicate glass and filled with solution containing $130 \mathrm{~mm}$ K-gluconate, 5 mм KCl, 10 mм HEPES, 0.6 mм EGTA, 4 mm Mg-ATP, $0.4 \mathrm{~mm} \mathrm{Na-GTP}$, and $10 \mathrm{~mm} \mathrm{Na}_{2}$ phosphocreatine (290 mOsm, pH 7.2). For AMPA/NMDA ratios, $\mathrm{K}$-gluconate and $\mathrm{KCl}$ were replaced by $115 \mathrm{~mm}$ Cs-methylsulfonate and $20 \mathrm{~mm} \mathrm{CsCl}$. Data were acquired using a Multiclamp 700B and pClamp software (Molecular Devices), and analyzed offline using Igor Pro (WaveMetrics). Resting membrane potential was measured after break-in, and input resistance was calculated from the slope of a linear fit to the current-voltage relation or steady state voltage steps. Excitatory synaptic inputs from Schaffer collaterals were evoked and measured as previously described (Ehrlich and Malinow, 2004). Paired-pulse ratios were obtained at a $50 \mathrm{~ms}$ interval. Light-evoked responses were measured using K-gluconate internal solution. For some experiments, a light- emitting diode (470 nm) (Cairn Research) was used to stimulate ChR, in other experiments, a metal-halide lamp was used in combination with a blue excitation filter (WIBA2, Olympus) for ChR and a yellow excitation filter (FF01593/40-25, AHF) for NpHR and a fast shutter (Uniblitz). Data are shown as mean \pm SEM; $n$ is the number of cells or cell pairs. For statistical comparisons, paired or unpaired Student's $t$ tests were used, as applicable.

\section{In vivo two-photon imaging}

Two-photon imaging was performed 3 weeks after virus injection into somatosensory cortex using a custom-built two-photon microscope (Hasan et al., 2004). Mice were anesthetized with urethane $(1.5 \mathrm{mg} / \mathrm{g}$ body weight), and body temperature was maintained at $37^{\circ} \mathrm{C}$. A custom-built head plate with an imaging window $(4 \times 3 \mathrm{~mm})$ was glued to the top of the skull using cyanoacrylate (Uhu) and attached to a fixed metal bar. The microscope objective was positioned so that the optical axis was perpendicular to the surface of the cortex. Twophoton image sequences were collected in regions of interest with a MicroMax, $512 \times 512$ back-illuminated CCD camera (Roper Scientific).

\section{Results}

Efficient $2 A$ peptide cleavage and coexpression in primary neurons

To examine $2 \mathrm{~A}$-mediated coexpression in neurons, we generated a modified $2 \mathrm{~A}$ peptide bridge from Thosea asigna virus (de
Felipe et al., 2006) by adding 4 aa to the C-terminal proline (Fig. 1A). Because C-terminal 2A peptide sequences had previously been reported to interfere with protein function (Lengler et al., 2005; Hasegawa et al., 2007), we reasoned that the addition of 4 aa may favor reproducible processing efficiency at the cleavage site by creating a constant environment.

First, we infected rat primary hippocampal neurons with rAAV encoding a 2A fusion protein between the nuclearlocalized iCre (Shimshek et al., 2002) and the FP Venus (Nagai et al., 2002) under the control of the human synapsin promoter (Fig. 1A). Ten days after infection, we found in Western blots of cell lysates high levels of released iCre and Venus together with low levels of the full-length protein, indicating efficient $2 \mathrm{~A}$ selfprocessing (Fig. 1B). The molecular weight (MW) of the released iCre2A was slightly bigger than "wild-type" iCre (39 $\mathrm{kDa}$ ) due to the short, remaining $2 \mathrm{~A}$ tail of 17 amino acid residues $(40.8 \mathrm{kDa})$. When compared with a similar construct expressed from a cytomegalovirus (CMV) promoter in heterologous HEK293 cells (supplemental Fig. $1 A, B$, available at www.jneurosci.org as supplemental material), the balance between newly synthesized full-length iCre2A-FP and the re- 
leased iCre2A and FPs appeared much more in favor of cleaved products in neurons (Fig. $1 B$ ), indicating that the $2 \mathrm{~A}$ strategy may be particularly suitable for coexpression in nondividing cells such as neurons or in the brain. We confirmed that the enzymatic activity of the released iCre2A fusion was completely intact by assaying Cre-mediated activation of lacZ expression in the Cre-reporter cell line CV1 (supplemental Fig. $1 C$, available at www.jneurosci.org as supplemental material). The $2 \mathrm{~A}$ self-processing was also supported by immunostaining of rAAVinfected primary hippocampal neurons, which detected iCre exclusively in the nucleus and Venus mainly in the cytosol. Even without enhancement, Venus expression was high enough to visualize fine cellular processes (Fig. 1C).

To directly compare the $2 \mathrm{~A}$ approach with conventional, dual-promotermediated coexpression, we used a bidirectional Ptet-bi promoter construct (Baron et al., 1995) (Fig. 1B; supplemental Fig. $1 A$, available at www.jneurosci.org as supplemental material). Using this bidirectional promoter, iCre levels were much lower than those obtained from the iCre2A-Venus fusion construct when normalized to the levels of Venus (data not shown). Assuming that iCre and Venus are released approximately in a oneto-one ratio from the iCre $2 \mathrm{~A}-\mathrm{V}$ enus fusion construct, the amount of iCre was approximately sixfold higher with the $2 \mathrm{~A}$ strategy than with the bidirectional promoter, demonstrating that expression levels at the left and right side of this bidirectional promoter were very different. In summary, using our modified $2 \mathrm{~A}$ peptide sequence results in effective processing of the expressed fusion protein and allows for the reliable and quantitative coexpression of proteins in heterologous cells and particularly in neurons.

\section{Functional coexpression in intact brain} and applications for electrophysiology and imaging ex vivo and in vivo

To examine 2A peptide-mediated coexpression in the brain in vivo, we injected rAAV-Syn-iCre2A-Venus into cortex and hippocampus of adult Cre-reporter Rosa26R mice (Soriano, 1999). Two weeks later, the expression of the Credependent lac $Z$ reporter gene indicated successful delivery of functional iCre2A (Fig. 2A). At the injection sites, cytosolic Venus fluorescence and nuclear iCre staining were colocalized in the same neurons, confirming efficient self-processing of iCre2A and Venus in vivo (Fig. $2 B, C$ ).
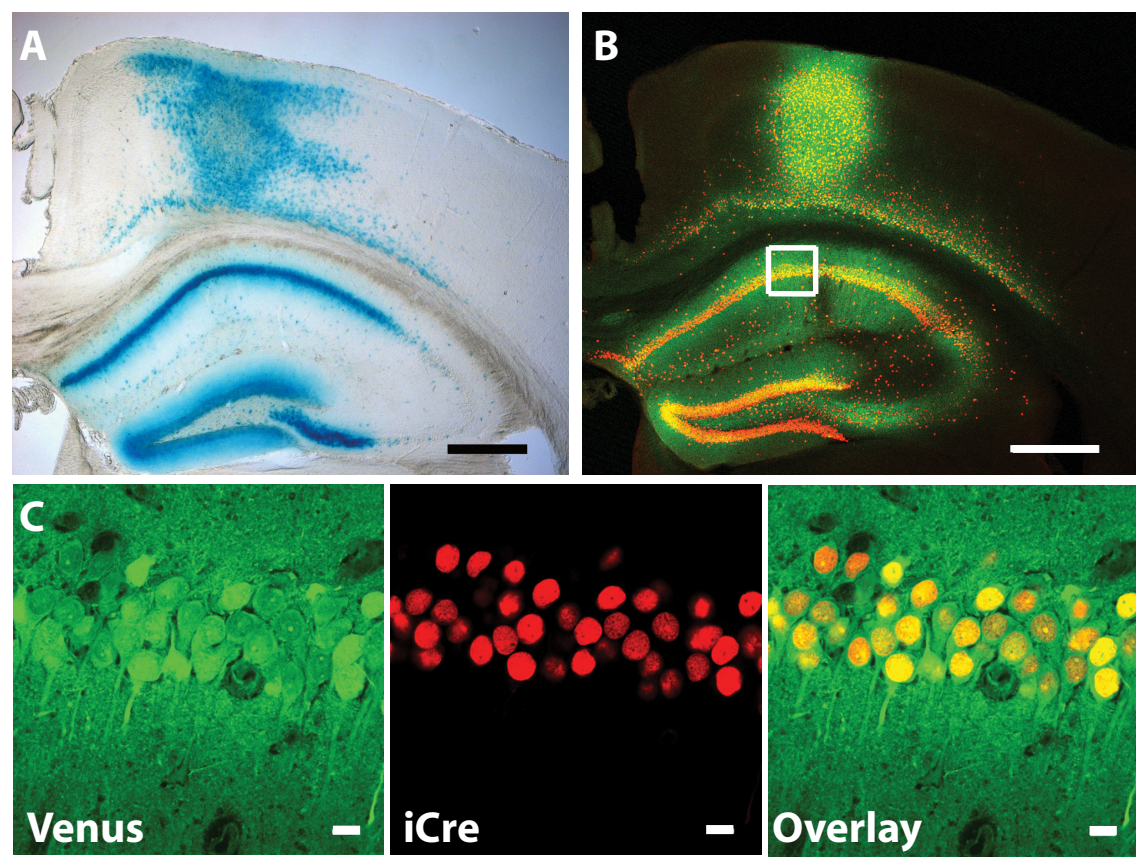

D
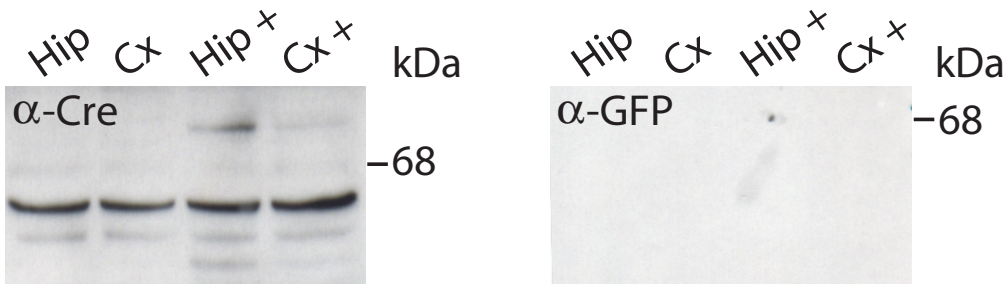

iCre2A

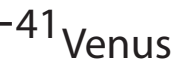

$-27$
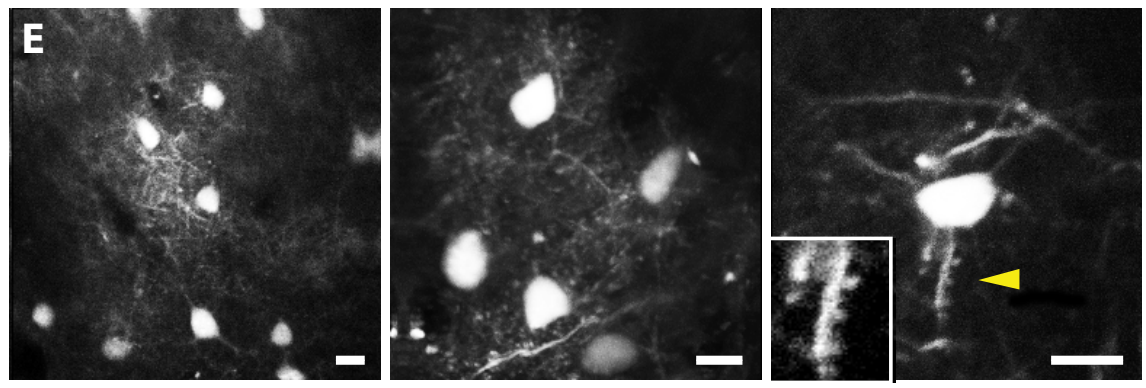

Figure 2. Functional and reliable coexpression using $2 \mathrm{~A}$ peptide bridges in vivo and its application in life imaging. $A$, LacZ staining of a brain section from a Rosa26R mouse 2 weeks after stereotactic injection of rAAV-Syn-iCre2A-Venus, indicating that the released iCre2A protein was functional in vivo. Only infected brain regions showed blue LacZ signal. Scale bars, $500 \mu \mathrm{m}$. $\boldsymbol{B}$, Confocal image of a brain section from a wild-type mouse injected with rAAV-Syn-iCre2A-Venus at DPI 14. Scale bars, $500 \mu \mathrm{m}$. C, Higher magnification of the boxed CA1 region. Coexpression of Venus (green) and iCre (red, visualized with Cy3-coupled antibody) was seen in virtually all infected neurons. Scale bars, $10 \mu \mathrm{m}$. D. Western blots of extracts from infected brain regions demonstrate near complete $2 \mathrm{~A}$ peptide self-processing in vivo. Tissues were dissected from brains of noninjected and $\mathrm{AAAV}-\mathrm{Syn}-\mathrm{iCre2A-Venus}$ injected C57BL/6 mice at DPI 14. The $40.8 \mathrm{kDa}$ iCre2A (left) and the $27.3 \mathrm{kDa}$ Venus (right) were clearly detected, the $68.1 \mathrm{kDa}$ full-length fusion protein was hardly visible. Hip, Hippocampus; $\mathrm{C}$, cortex; + , infected with rAAV. $\boldsymbol{E}$, In vivo two-photon images of a mouse injected with purified rAAV-Syn-iCre2A-Venus in somatosensory cortex at DPI 21. Cell bodies of neurons in superficial layers as well as their fine processes were imaged at a depth of 150-200 $\mu \mathrm{m}$. Spines are indicated by arrowhead and zoom-in image is shown. Scale bars, $10 \mu \mathrm{m}$.

In Western blots, we detected exclusively the released iCre2A and Venus, but not the full-length iCre2A-Venus fusion protein (Fig. 2D).

Next, we examined whether expression levels of FPs would be sufficient to enable high-resolution imaging of neurons and their processes in the intact brain in vivo. Indeed, 3 weeks after infection with rAAV-Syn-iCre2A-Venus, fluorescence was strong enough to allow for imaging of cortical neurons in anesthetized 

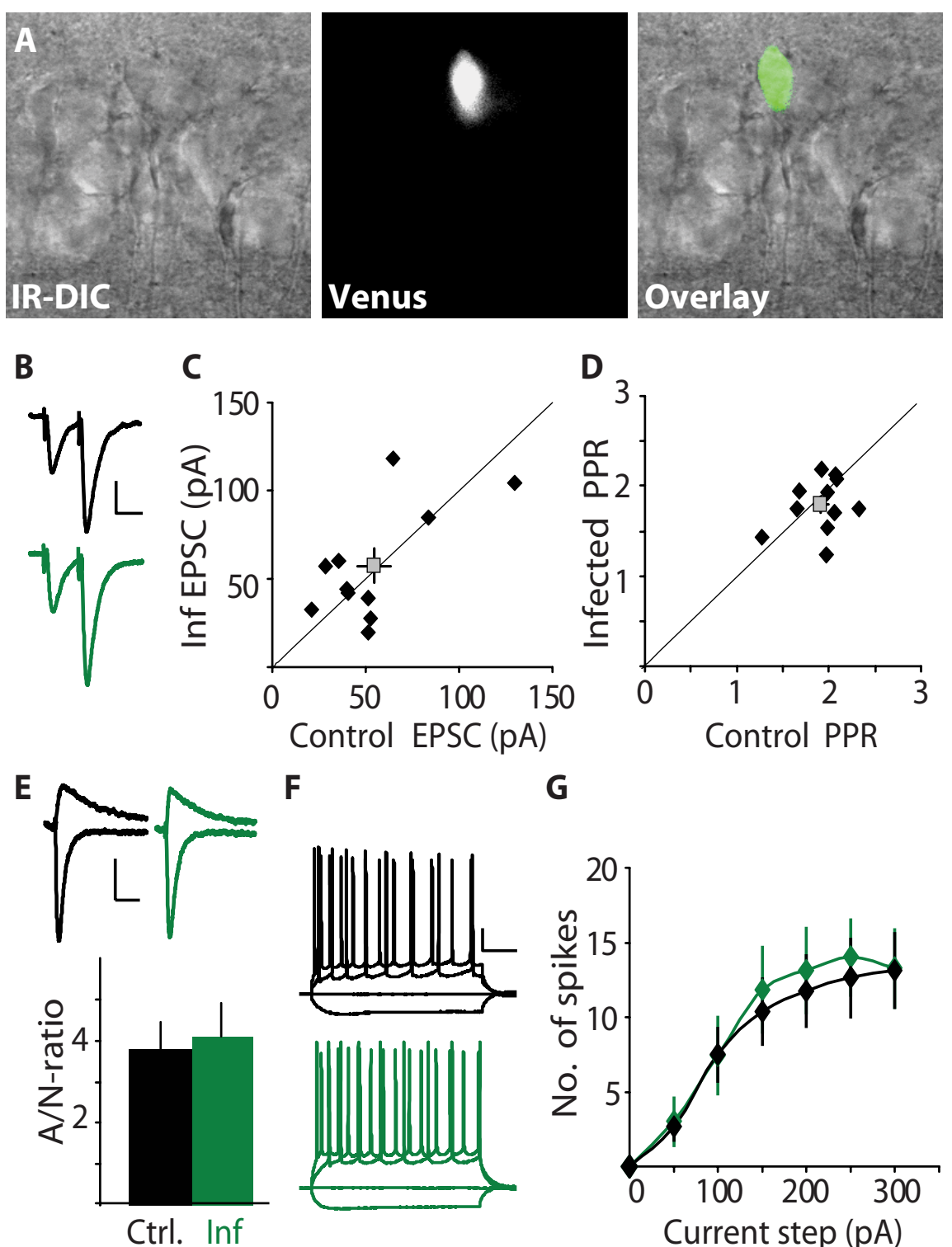

$\mathbf{F}$
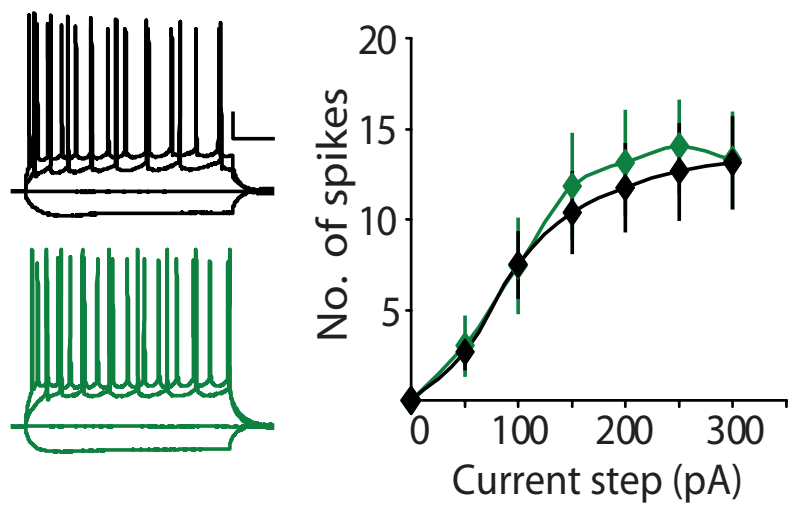

Figure 3. Unaltered electrophysiological properties of neurons expressing 2A constructs. Viral expression of $2 A$ constructs had no effect on viability, spiking behavior, and synaptic transmission. $\boldsymbol{A}$, Sparsely infected CA1 region in an acute hippocampal slice of rAAV-Syn-iCre2A-Venus at DPI 14-21, where Venus-expressing cells are clearly seen. $\boldsymbol{B}$, AMPA-EPSCs recorded from a pair of CA1 neurons in response to paired pulses at $-70 \mathrm{mV}$; control (black) and infected cell (green). Calibration: 20 pA, 40 ms. C, No difference in amplitudes of AMPA-EPSCs, which were $-54.4 \pm 9.2 \mathrm{pA}$ and $-57.4 \pm 9.7 \mathrm{pA}$ in control and infected neurons, respectively ( $n=11$ pairs, $p=0.68$ ). $\boldsymbol{D}$, No alterations in paired-pulse ratios (PPRs) of AMPA-EPSCs, which were $1.91 \pm 0.09$ and $1.79 \pm 0.09$ in control and infected neurons, respectively $(n=11$ pairs, $p=0.56)$. $\boldsymbol{E}$, AMPA- and NMDA-mediated EPSCs recorded from a pair of CA1 neurons at $-70 \mathrm{mV}$ and $+40 \mathrm{mV}$; control (black) and infected cell (green). Calibration: $20 \mathrm{pA}, 50 \mathrm{~ms}$. There was no change in AMPA/NMDA ratios, which were $3.80 \pm 0.63(n=6)$ and $4.09 \pm 0.84(n=5)$ in control and infected neurons, respectively ( $p=0.74)$. $\boldsymbol{F}$, Indistinguishable electrical properties of control and infected CA1 neurons. Responses of a control (black) and an infected (green) neuron to current injections of $-100,0,+100$, and +200 pA. Calibration: $20 \mathrm{mV}, 100 \mathrm{~ms}$. $\mathbf{G}$, No difference in input-output curves (control, $n=8$, infected, $n=7 ; p>0.72$ ).

mice by two-photon microscopy. The labeled neurons and their processes, including spines, were readily visible in the superficial cortical layers (Fig. 2E). These experiments not only demonstrate that expression levels were high enough for subcellular imaging, but also that our rAAVs were purified well enough to avoid immune responses, cell damage, or necrosis.
To confirm at a more subtle level that rAAV-infected neurons expressing 2Aconstructs displayed the same physiological parameters as uninfected counterparts, we recorded from Venusexpressing cells in acute brain slices ex vivo 3 weeks after infection. Hippocampal pyramidal neurons infected with $\mathrm{rAAV}$-SyniCre $2 \mathrm{~A}-\mathrm{Venus}$ were viable and easy to identify by their green fluorescence (Fig.
$3 A$ ). The postsynaptic properties (measured by AMPA to NMDA ratio) and presynaptic function (measured by pairedpulse ratio) were indistinguishable from neighboring nonfluorescent cells (Fig. $3 B-E)$. We also found no difference in the passive electrical properties (supplemental Table 1, available at www.jneurosci.org as supplemental material), intrinsic excitability, and spiking behavior between infected and control neurons (Fig. $3 F, G$ ). Hence, rAAV-driven coexpression of $2 \mathrm{~A}$ self-processing proteins does not influence neuronal properties and induce cell toxicity. We conclude that our 2A peptide strategy has the powerful potential to combine genetic manipulations with the expression of FPs in subgroups of neurons, a prerequisite for functional studies using optical and electrophysiological high-resolution analysis in vivo, in particular for long-term investigations.

Functional coexpression of itTA or secreted proteins with fluorescent proteins

To demonstrate that the self-processing activity of the modified $2 \mathrm{~A}$ peptide was independent of the fused protein domains, we extended our strategy to other activators used for conditional gene expression, and other FPs. We generated rAAVs expressing a fusion protein between the itTA (Krestel et al., 2004) and the red FP KO (Karasawa et al., 2004) (Fig. $4 A)$. When expressed in cultured primary hippocampal neurons, itTA2A was released (Fig. $4 B$ ). To provide proof of principle that itTA2A and KO were coexpressed and active in vivo, we coinjected rAAV-Syn-itTA2A-KO and a tTA responder virus rAAV-Ptetbi-iCre-Venus (Zhu et al., 2007) into the cortex and hippocampus of wild-type mice. We observed activation of the tTA responder genes in infected neurons, as assessed by Venus fluorescence. The FPs, Venus and $\mathrm{KO}$, colocalized in most neurons at the injection site, suggesting a high rate of neurons coinfected with both viruses (Fig. $4 C, D)$. Even when we consider the constraints of coinfection and promoter leakiness of the responder virus (Zhu et al., 2007), our data provide strong evidence that $2 \mathrm{~A}$ self-processing with our modified sequence is independent of the fused proteins and can be used universally.

To examine whether our $2 \mathrm{~A}$ approach is also effective for fusion proteins synthesized at the rough endoplasmic reticulum (ER) that undergo cotranslational secretion, we introduced the secreted protein Noggin with a signal peptide at its $\mathrm{N}$ terminus as a $2 \mathrm{~A}$ fusion with Venus (Fig. $4 E$ ). 
We infected primary hippocampal neuron cultures with rAAV-Syn-Noggin2AVenus, and when Venus fluorescence could be detected $10 \mathrm{~d}$ later, we analyzed cell lysates and the culture medium by Western blotting. In cell lysates, three proteins with MWs of 32, 30, and $26 \mathrm{kDa}$ could be detected. The $26 \mathrm{kDa}$ form represents the unmodified Noggin2A, the 30 $\mathrm{kDa}$ protein the glycosylated Noggin $2 \mathrm{~A}$, and the $32 \mathrm{kDa}$ protein is the mature Noggin2A, which is glycosylated and contains a cystine knot motif that is resistant to regular reduction procedures (Groppe et al., 2002). Importantly, in the medium, we only detected the $32 \mathrm{kDa}$ isoform, suggesting successful secretion of Noggin $2 \mathrm{~A}$ after its release from the Noggin $2 \mathrm{~A}-\mathrm{Venus}$ fusion (Fig. $4 E$ ). As in previous experiments, the full-length Noggin2A-Venus fusion protein was not detected in cell lysates or in the medium. We conclude that 2A self-processing also occurs at the rough ER, and can be successfully applied to reliably coexpress secreted proteins and fluorescent markers in individual neurons.

\section{Coexpression of multiple membrane} proteins and fluorescent reporters

Another highly desirable application is to faithfully coexpress untagged membrane proteins, such as ion channels or receptors, together with FPs. Quantitative coexpression of several membrane proteins together with FPs is particularly useful for studying function of circuits and synapses. Here, we tested this possibility using one or multiple $2 \mathrm{~A}$ peptide bridges. We generated fusion constructs between the light-gated ion channel $\mathrm{ChR}$ or the ion pump NpHR and FPs, and a triple construct coexpressing $\mathrm{ChR}, \mathrm{NpHR}$, and an FP using two 2A elements (Fig. 5A). The function of these light-activated proteins is easily assessed by electrophysiology and permits bidirectional light-gated control of neuronal activity (Gradinaru et al., 2007). We first transfected all pAAV constructs biolistically into hippocampal slice cultures before producing the respective viruses. Transfected cells were viable and exhibited normal basic electrical properties when compared with neighboring control neurons (supplemental Table 1, available at www.jneurosci.org as supplemental material). Importantly, FPs were always localized in the cytosol and in the nucleus, indicating that they were freely diffusible, and therefore, were cleaved products of the 2A fusion proteins (Fig. $5 A)$. Neurons transfected with ChR2AtDimer, identified by red fluorescence,
A

I rAAV-Syn-itTA2A-KO

\begin{tabular}{c|c||c|c}
\multicolumn{1}{c}{$29 \mathrm{kDa}$} & $25 \mathrm{kDa}$ \\
\hline Syn P & itTA & 2A & KO \\
\hline
\end{tabular}

II rAAV-Ptetbi-iCre-Venus

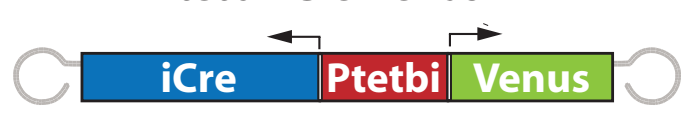

B
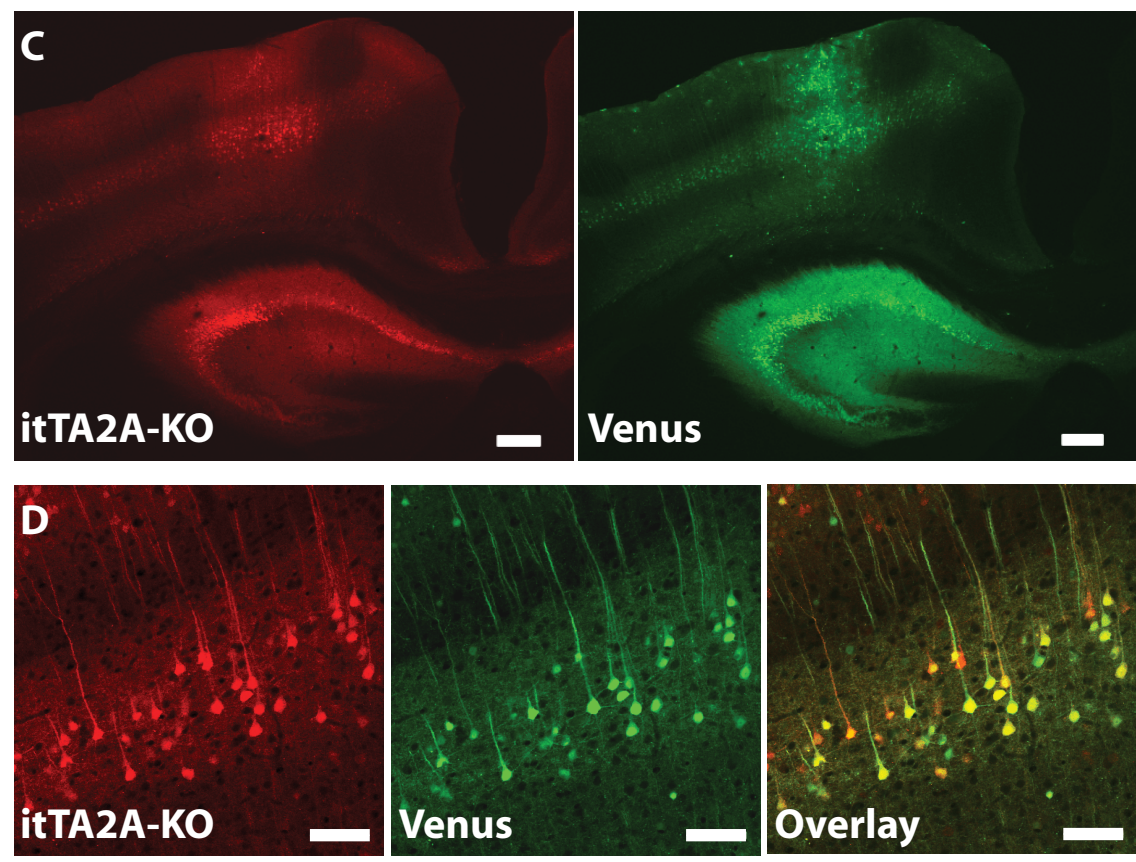

E rAAV-Syn-Noggin2A-Venus

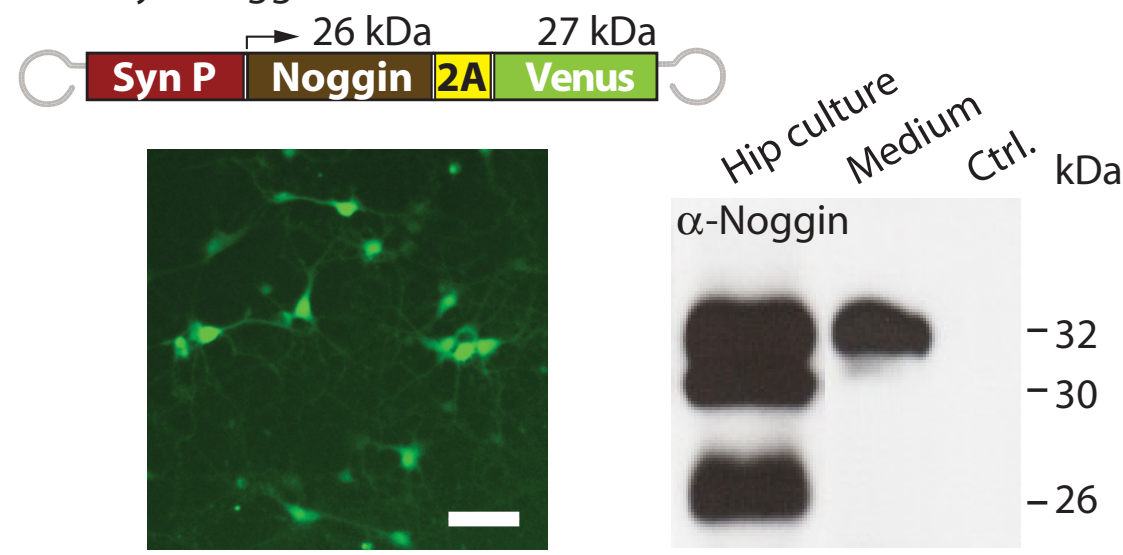

Figure 4. Use of 2A strategy to express other activators, fluorescent proteins, and secreted proteins. $\boldsymbol{A}$, Diagram of the rAAVs for dual virus activator-responder approach to test for itTA and $\mathrm{KO}$ coexpression by $2 \mathrm{~A}$ self-processing. $\boldsymbol{B}$, Western blots of protein extracts from rAAV-Syn-itTA2A-K0-infected dissociated hippocampal neuron in culture at DPI 10. The 30.5 kDa itTA2A fusion protein was detected and $55.4 \mathrm{kDa}$ full-length protein was faintly visible. I+ II, Coinfected neurons. Ctrl, Noninfected neurons. $\boldsymbol{C}$, Confocal images of a brain section from a mouse coinjected with rAAV-Syn-itTA2A-K0 and the responder virus rAAV-Ptetbi-iCreVenus $14 \mathrm{~d}$ after injection. Cells expressing itTA are labeled with the coexpressed red fluorescent protein $\mathrm{KO}$. The itTA-driven Venus expression from the responder virus was detected by green fluorescence. Scale bars, $200 \mu \mathrm{m}$. D, At higher magnification, many neurons were fluorescently labeled in the infected cortical area, and most of them showed coexpression of KO and Venus as expected. Scale bars, $50 \mu \mathrm{m}$. $\boldsymbol{E}$, Left, Dissociated primary hippocampal neurons at DPI 10 with rAAV-Syn-Noggin2A-Venus. Right, Western blots from rAAV-Syn-Noggin2A-Venus-infected primary hippocampal cultures at DPI 10. Three different forms of Noggin were detected in hippocampal neuron lysate, and only the $32 \mathrm{kDa}$ secreted form was detected in the culture medium. Ctrl, Noninfected neurons. 
A I pAAV-Syn-ChR2A-tDimer \begin{tabular}{l|l||l|l|} 
Syn P & ChR2 & 2A Dimer \\
\hline
\end{tabular}

II pAAV-Syn-NpHR2A-Venus \begin{tabular}{|l|l||l|l|}
\hline Syn P & NpHR & 2Aenus \\
\hline
\end{tabular}

III pAAV-Syn-ChR2A-NpHR2A-Venus

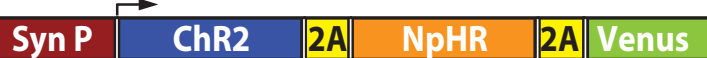

$\|$

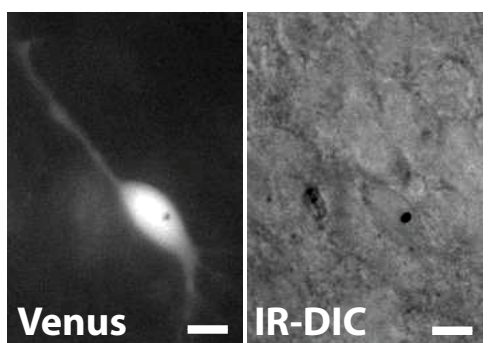

B I

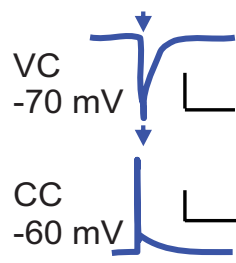

C

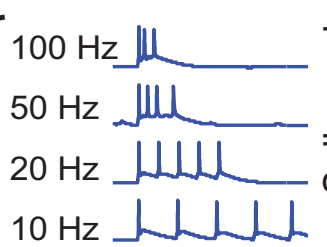

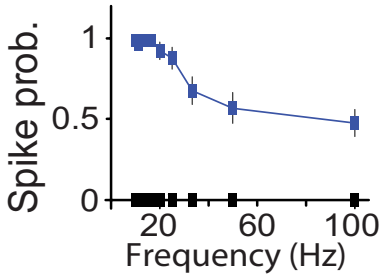

Frequency $(\mathrm{Hz})$
D

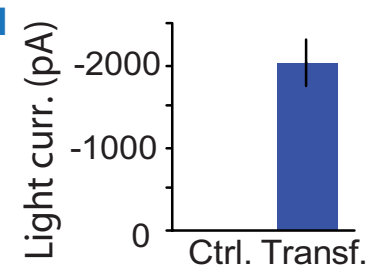

E II

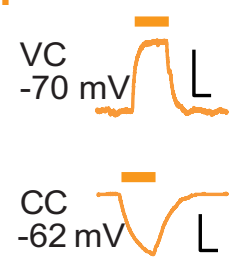

F No Stim.

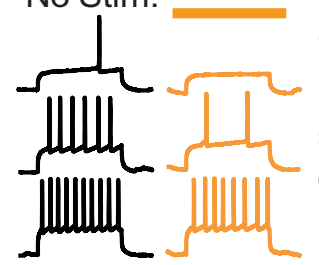

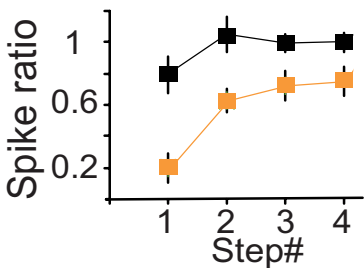

G

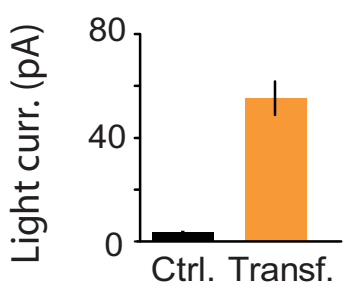

H III

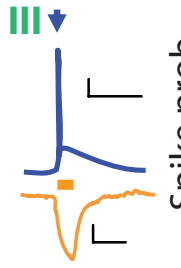

CC $-59 \mathrm{mV}$

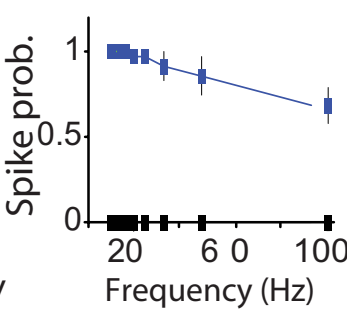

I No Stim.

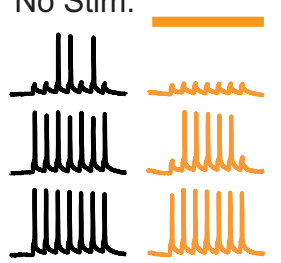

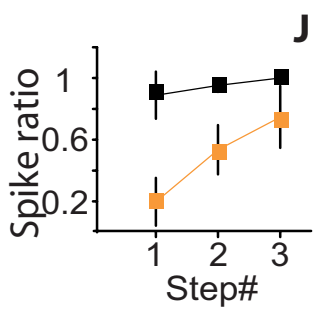

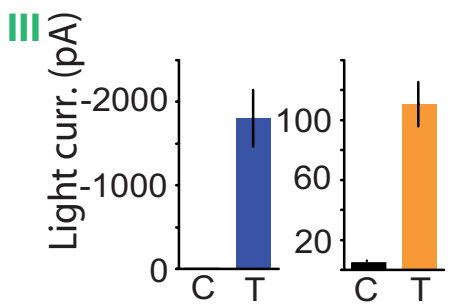

K I rAAV-Syn-ChR2A-tDimer \begin{tabular}{|l|l|l|l|}
\hline Syn P & ChR2 & 2A Dimer \\
\hline
\end{tabular}

L III rAAV-Syn-ChR2A-NpHR2A-Venus

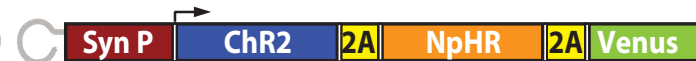
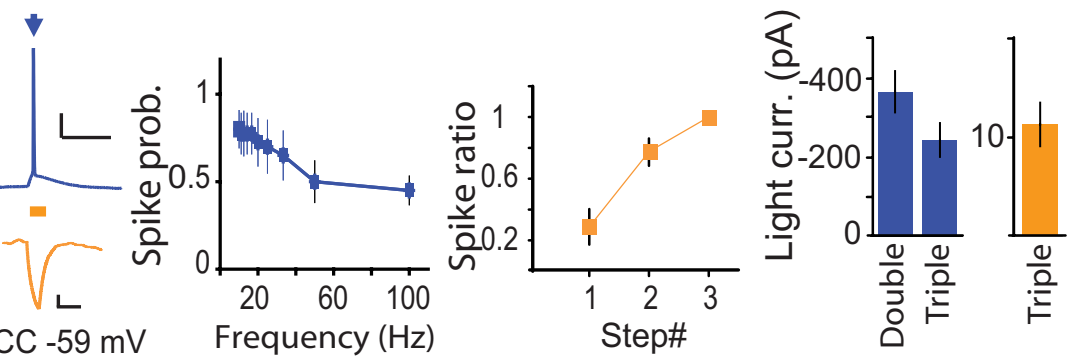

Figure 5. Functional coexpression of multiple membrane proteins and a fluorescent reporter. $\boldsymbol{A}$, Left, Diagram of pAAV plasmids. Right, Infrared and fluorescence images of a plasmid-transfected pyramidal neuron in an organotypic slice expressing ChR2A-NpHR2A-Venus. Scale bar, $10 \mu \mathrm{m}$. B, Light responses in a transfected pyramidal neuron expressing ChR2A-tDimer in organotypic slices. Blue light (2 ms) elicited an inward current in voltage clamp (VC) and a spike in current-clamp mode (CC). Calibration: VC, 2000 pA, 100 ms; CC, 40 mV, 100 ms. C, Light-induced spiking at different stimulation frequencies, and summary of spike probability as a function of frequency in transfected cells (blue symbols; $n=13$ ). No spikes were seen in control cells (black symbols; $n=6$ ). $\boldsymbol{D}$, Blue light-evoked ChR-currents were $-2009 \pm 304 \mathrm{pA}(n=9)$ versus $-3 \pm 1 \mathrm{pA}(n=6)$ in transfected versus control cells $(p<0.01)$. $\boldsymbol{E}$, Light responses in a transfected pyramidal neuron expressing NpHR2A-Venus. Yellow light (50 ms) elicited an outward current in VC, and a hyperpolarization in CC mode. Calibration: VC, 40 pA, 50 ms; CC, 10 mV, 50 ms. $\boldsymbol{F}$, Attenuation of spiking in pAAV-Syn-NpHR2A-Venus-transfected cells. Spikes evoked by current steps of increasing size in absence and presence of yellow light. The average spike ratio (number of spikes with/without light) was reduced for several step sizes in transfected (yellow symbols; $n=12$ ) versus control cells (black symbols; $n=12, p<0.02$ ). $G$, Yellow light-evoked NpHR currents were $55 \pm 7 \mathrm{pA}(n=12$ ) versus $4 \pm 1 \mathrm{pA}(n=12)$ in transfected versus control cells $(p<0.01)$. $\boldsymbol{H}$, Light responses in a pyramidal neuron expressing ChR2A-NpHR2A-Venus. Blue light $(2 \mathrm{~ms})$ elicited a spike, and yellow light (50 ms) elicited a hyperpolarization. Calibration: Top, $20 \mathrm{mV}, 100 \mathrm{~ms}$; bottom, $2 \mathrm{mV}, 100 \mathrm{~ms}$. High fidelity spiking in transfected cells (blue symbols; $n=7$ ), but not in control cells (black symbols; $n=9) . I$, In the same cells, NpHR activation attenuated neural firing evoked by short current steps. The average spike ratio was significantly reduced for the first two step sizes in transfected (yellow symbols; $n=8$ ) versus control cells (black symbols; $n=6, p<0.05)$. J, Blue light-evoked ChR-currents were $-1803 \pm 342 \mathrm{pA}(n=7)$ versus $-10 \pm 3 \mathrm{pA}(n=9)$ in transfected versus control cells $(p<0.01)$. Yellow light-evoked NpHR-currents were $111 \pm 15 \mathrm{pA}(n=7)$ versus $4 \pm 1 \mathrm{pA}(n=9)$ in transfected versus control cells $(p<0.01)$. $\boldsymbol{K}-\boldsymbol{M}$, Light $($ Figure legend continues.) 
showed large inward currents (in voltageclamp mode) or depolarizing responses (in current-clamp mode) when exposed to blue light (Fig. 5B). Train stimulation reliably induced action potentials, even at high frequencies (Fig. 5C). When NpHR2A-Venus-transfected cells, identified by green fluorescence, were exposed to yellow light, outward light-induced currents (in voltage-clamp mode) and hyperpolarizing responses (in currentclamp mode) were recorded (Fig. 5E). Light-evoked hyperpolarizations significantly reduced action potential firing (Fig. $5 F)$. For bidirectional optogenetic control, we expressed a construct encoding both light-activated proteins together with a soluble FP (pAAV-Syn-ChR2ANpHR2A-Venus) (Fig. 5A). All transfected neurons responded to both blue and yellow light (Fig. 5H). Light-activated currents were of similar or even larger amplitude when compared with cells transfected with only one of the light-gated proteins, demonstrating efficient selfprocessing and equal function when expressed from the dual versus triple construct (Fig. 5D, G,J). Moreover, efficient, bidirectional control of action potential firing was achieved in the same neurons (Fig. $5 H, I$ ). To test suitability of this method for in vivo applications, we generated rAAVs expressing ChR2A-tDimer and ChR2A-NpHR2A-Venus. Amygdala neurons were infected in vivo, and lightgated activity was subsequently assayed $e x$ vivo in acute brain slices. For both constructs, infected neurons showed no signs of cellular toxicity, and had stable resting membrane potentials and electrical properties (data not shown). All neurons infected with rAAV-Syn-ChR2A-tDimer displayed light-evoked currents, and in $69 \%(n=20 / 29)$ expression levels were high enough to induce light-evoked spik-

\footnotetext{
(Figure legend continued.) responses of amygdala neurons in acute slices after rAAV infection in vivo. $\boldsymbol{K}$, Blue light (2 ms) induced an inward current or spiking in a neuron infected with rAAV Syn-ChR2A-tDimer. Calibration: VC, 100 pA, 100 ms; CC, $20 \mathrm{mV}, 100 \mathrm{~ms}$. Spike probability of infected neurons at different stimulation frequencies $(n=18)$. L, Blue ( $2 \mathrm{~ms}$ ) or yellow $(50 \mathrm{~ms})$ light evoked a spike or hyperpolarization, respectively, in a neuron infected with rAAV-Syn-ChR2A-NpHR2AVenus. Calibration: Top, $20 \mathrm{mV}$, $100 \mathrm{~ms}$; bottom, $0.5 \mathrm{mV}$, 100 $\mathrm{ms}$. Blue light stimulation induced spiking with high fidelity $(n=8)$. Yellow light pulses effectively reduced spiking for the first two current steps compared with no light stimulation ( $n=14, p<0.01) . M$, Light-evoked currents in cells infected with either rAAV-Syn-ChR-2A-tDimer (double) or rAAV-SynChR2A-NpHR2A-Venus (triple). Blue light-evoked currents were $-365 \pm 52 \mathrm{pA}$ (double) and $-243 \pm 43 \mathrm{pA}$ (triple). Yellow light-evoked currents were $11 \pm 2 \mathrm{pA}$ (triple).
}

ing with high fidelity (Fig. $5 \mathrm{~K}$ ). For rAAVSyn-ChR2A-NpHR2A-Venus, all neurons with Venus fluorescence showed light-evoked currents. Effective bidirectional optic control of neural activity (spiking or attenuation of spiking) was achieved in $77 \%(n=14 / 18)$ of recorded cells (Fig. $5 \mathrm{~L}$ ). Although all recorded cells showed light-evoked currents (Fig. 5M), in some cells they were not large enough to control action potential firing. This could be explained by heterogeneous expression levels caused by differences in infection rates or in the number of infecting virus particles per cell.

In addition to our functional data suggesting efficient self-processing of the ChR and NpHR constructs, we sought to confirm this biochemically. We used plasmid transfection or virus infection to express rAAV-Syn-ChR2A-tDimer and rAAV-Syn-ChR2A-NpHR2A-Venus in primary hippocampal neuron cultures. Western blot analysis of these constructs revealed undetectable levels of the fulllength proteins $(89.9 \mathrm{kDa}$ and $98.8 \mathrm{kDa}$, respectively) and released tDimer or $\mathrm{Ve}$ nus (supplemental Fig. $2 B, C$, available at www.jneurosci.org as supplemental material). The Venus signal intensity from the rAAV triple construct was comparable to that from rAAV-Syn-iCre2A-Venusinfected neurons (supplemental Fig. 2C, available at www.jneurosci.org as supplemental material), indicating that for the triple construct, FP expression levels were not severely compromised. Together, our data strongly argue that the 2A strategy can be used to quantitatively coexpress up to two functional membrane proteins together with fluorescent markers in slice cultures and in vivo for labeling as well as faithful bidirectional optogenetic control of individual neurons.

\section{Discussion}

Considering the difficulties to achieve reliable coexpression of heterologous proteins using current approaches, such as IRES (Douin et al., 2004) elements, bidirectional or dual promoters (Baron et al., 1995), cotransfection of several plasmids, or coinfection with multiple viruses (Mastakov et al., 2002), it is surprising that the use of $2 \mathrm{~A}$ peptide bridges has not received more attention (Furler et al., 2001; de Felipe et al., 2006). One particular advantage of the $2 \mathrm{~A}$ system is the use of only a single promoter that can be cell-type specific. A second one is its small size, and therefore the potential to design constructs with several 2A elements for expression of multiple proteins, even in vector systems with stringent size restrictions. And thirdly, in view of the well justified assumption that the cleaved proteins from a $2 \mathrm{~A}$ fusion protein are translated and released in equimolar ratios (de Felipe et al., 2006), the $2 \mathrm{~A}$ system would allow for quantification of the coexpressed proteins by measuring the level of the fluorescent reporter within and across experiments.

In the present study, we demonstrate that the $2 \mathrm{~A}$ peptide approach can be used in neurons and in the brain in vivo for reliable and quantitative coexpression. When compared with heterologous cells, 2A cleavage was always more efficient in neurons and in the brain with undetectable levels of unprocessed 2A fusion proteins. Most importantly, all 2A fusion proteins retained their biological activities, without detectable consequences for neuronal viability and function.

In contrast to our findings, previous studies reported that reporters such as DsRed and the humanized Renilla GFP with the FMDV $2 \mathrm{~A}$ peptide at their $\mathrm{C}$ terminus, were functionally inactive (Lengler et al., 2005; Hasegawa et al., 2007), or mislocalization of the second gene products occurred (de Felipe and Ryan, 2004). A careful design of the $2 \mathrm{~A}$ fusion constructs, and perhaps use of the additional amino acid residues to retain a stable environment for self-processing at the cleavage sites may be a key feature that made our approach successful and broadly applicable. However, we cannot exclude that other proteins with critical C-terminal elements such as glutamate receptor subunits (Kessels and Malinow, 2009) or neomycin phosphotransferase II (Reiss et al., 1984) may not be able to function when expressed as $2 \mathrm{~A}$ fusion proteins.

In all our experiments, the levels of FPs were high enough for both imaging in vivo and targeting of cells for electrophysiology, but a direct comparison with single expression of FP is difficult. In virusmediated gene transfer, expression levels always depend on a number of factors, such as the gene itself, the viral titer, and the mode of application in vivo. We expressed fluorescent reporters as C-terminal partners in the $2 \mathrm{~A}$ fusion proteins. As the translation efficiency of the 2A fusion proteins is determined by translation initiation at the start codon of the variable $\mathrm{N}$-terminal encoded proteins, additional studies with $\mathrm{N}$-terminal FPs would be needed to clarify whether the sensitivity of the FPs suffers in the 2A approach. However, for most applications a C-terminal located FP should be considered, since most likely the activity of the 
FPs reflects the expression efficiency of the $\mathrm{N}$-terminal proteins as well. A limiting factor for interpreting quantitative, equimolar expression of the $\mathrm{N}$ - and C-terminal proteins in the $2 \mathrm{~A}$ fusion constructs is the potential of different half lives of the released proteins. Stabilizing and nonstabilizing motifs in the individual proteins could lead to unbalanced protein turnover and thus different levels, even when they are expressed from a single ORF.

In our study, we emphasize that efficient coexpression of potent genetic regulators, such as iCre and tTA, in 2A fusions with different FPs permitted the reliable visualization of conditionally regulated neurons in fixed tissue and in vivo. Furthermore, we provide clear evidence that the $2 \mathrm{~A}$ peptide bridge approach can be applied to secreted and membrane proteins, and up to three functionally intact proteins can be expressed linked by several $2 \mathrm{~A}$ peptides. This allows, for instance, to reliably control the activity of the defined neurons in a bidirectional manner by quantitative coexpression of $\mathrm{ChR}$ and NpHR.

Overall, we conclude that the $2 \mathrm{~A}$ peptide bridge is a very versatile tool for coexpression of multiple heterologous proteins in neurons in vitro and in vivo, which will greatly facilitate molecular and functional analysis in cellular and systems neuroscience.

\section{References}

Baron U, Freundlieb S, Gossen M, Bujard H (1995) Co-regulation of two gene activities by tetracycline via a bidirectional promoter. Nucleic Acids Res 23:3605-3606.

Bissière S, Humeau Y, Lüthi A (2003) Dopamine gates LTP induction in lateral amygdala by suppressing feedforward inhibition. Nat Neurosci 6:587-592.

Brewer GJ, Torricelli JR, Evege EK, Price PJ (1993) Optimized survival of hippocampal neurons in B27-supplemented neurobasal, a new serum-free medium combination. J Neurosci Res 35:567-576.

Campbell RE, Tour O, Palmer AE, Steinbach PA, Baird GS, Zacharias DA, Tsien RY (2002) A monomeric red fluorescent protein. Proc Natl Acad Sci U S A 99:7877-7882.

Cetin A, Komai S, Eliava M, Seeburg PH, Osten P (2006) Stereotaxic gene delivery in the rodent brain. Nat Protoc 1:3166-3173.

Dalby B, Cates S, Harris A, Ohki EC, Tilkins ML, Price PJ, Ciccarone VC (2004) Advanced transfection with Lipofectamine 2000 reagent: primary neurons, siRNA, and highthroughput applications. Methods 33:95-103.

de Felipe P, Ryan MD (2004) Targeting of proteins derived from self-processing polyproteins containing multiple signal sequences. Traffic 5:616-626.

de Felipe P, Luke GA, Hughes LE, Gani D, Halpin C, Ryan MD (2006) E unum pluribus: multiple proteins from a self-processing polyprotein. Trends Biotechnol 24:68-75.

Donnelly ML, Luke G, Mehrotra A, Li X, Hughes LE, Gani D, Ryan MD (2001) Analysis of the aphthovirus $2 \mathrm{~A} / 2 \mathrm{~B}$ polyprotein 'cleavage' mechanism indicates not a proteolytic reaction, but a novel translational effect: a putative ribosomal 'skip.' J Gen Virol 82:1013-1025.

Douin V, Bornes S, Creancier L, Rochaix P, Favre G, Prats AC, Couderc B (2004) Use and comparison of different internal ribosomal entry sites (IRES) in tricistronic retroviral vectors. BMC Biotechnol 4:16.

Ehrlich I, Malinow R (2004) Postsynaptic density controls AMPA-receptor incorporation during long-term potentiation and experience-driven synaptic plasticity. J Neurosci 24:916-927.

Furler S, Paterna JC, Weibel M, Büeler H (2001) Recombinant AAV vectors containing the foot and mouth disease virus $2 \mathrm{~A}$ sequence confer efficient bicistronic gene expression in cultured cells and rat substantia nigra neurons. Gene Ther 8:864-873.

Gradinaru V, Thompson KR, Zhang F, Mogri M, Kay K, Schneider MB, Deisseroth K (2007) Targeting and readout strategies for fast optical neural control in vitro and in vivo. J Neurosci 27:14231-14238.

Gradinaru V, Thompson KR, Deisseroth K (2008) eNpHR: a Natronomonas halorhodopsin enhanced for optogenetic applications. Brain Cell Biol 36:129-139.

Groppe J, Greenwald J, Wiater E, Rodriguez-Leon J, Economides AN, Kwiatkowski W, Affolter M, Vale WW, Belmonte JC, Choe S (2002) Structureal basis of BMP signalling inhibition by the cystine knot protein Noggin. Nature 420:636-642.

Hasan MT, Friedrich RW, Euler T, Larkum ME, Giese G, Both M, Duebel J, Waters J, Bujard H, Griesbeck O, Tsien RY, Nagai T, Miyawaki A, Denk W (2004) Functional fluorescent $\mathrm{Ca}^{2+}$ indicator proteins in transgenic mice under TET control. PloS Biol 2:e163.

Hasegawa K, Cowan AB, Nakatsuji N, Suemori H (2007) Efficient multicistronic expression of a transgene in human embryonic stem cells. Stem Cells 25:1707-1712.

Hennecke M, Kwissa M, Metzger K, Oumard A, Kröger A, Schirmbeck R, Reimann J, Hauser $\mathrm{H}$ (2001) Composition and arrangement of genes define the strength of IRES-driven translation in bicistronic mRNAs. Nucleic Acids Res 29:3327-3334.

Karasawa S, Araki T, Nagai T, Mizuno H,
Miyawaki A (2004) Cyan-emitting and orange-emitting fluorescent proteins as a donor/acceptor pair for fluorescence resonance energy transfer. Biochem J 381:307-312.

Kessels HW, Malinow R (2009) Synaptic AMPA receptor plasticity and behavior. Neuron 61:340-350.

Krestel HE, Shimshek DR, Jensen V, Nevian T, Kim J, Geng Y, Bast T, Depaulis A, Schonig K, Schwenk F, Bujard H, Hvalby Ø, Sprengel R, Seeburg PH (2004) A genetic switch for epilepsy in adult mice. J Neurosci 24:10568-10578.

Lengler J, Holzmüller H, Salmons B, Günzburg WH, Renner M (2005) FMDV-2A sequence and protein arrangement contribute to functionality of CYP2B1-reporter fusion protein. Anal Biochem 343:116-124.

Mastakov MY, Baer K, Symes CW, Leichtlein CB, Kotin RM, During MJ (2002) Immunological aspects of recombinant adeno-associated virus delivery to the mammalian brain. J Virol 76:8446-8454

Nagai T, Ibata K, Park ES, Kubota M, Mikoshiba K, Miyawaki A (2002) A variant of yellow fluorescent protein with fast and efficient maturation for cell-biological applications. Nat Biotechnol 20:87-90.

Reiss B, Sprengel R, Schaller H (1984) Protein fusion with the kanamycin resistance gene from transposon Tn5. EMBO J 3:3317-3322.

Ryan MD, King AM, Thomas GP (1991) Cleavage of foot-and-mouth disease virus polyprotein is mediated by residues located within a 19 amino acid sequence. J Gen Virol 72:2727-2732.

Shevtsova Z, Malik JM, Michel U, Bähr M, Kügler S (2005) Promoters and serotypes: targeting of adeno-associated virus vectors for gene transfer in the rat central nervous system in vitro and in vivo. Exp Physiol 90:53-59.

Shimshek DR, Kim J, Hübner MR, Spergel DJ, Buchholz F, Casanova E, Stewart AF, Seeburg PH, Sprengel R (2002) Codon-improved Cre recombinase (iCre) expression in the mouse. Genesis 32:19-26.

Soriano P (1999) Generalized lacZ expression with the ROSA26 Cre reporter strain. Nat Genet 21:70-71.

Stoppini L, Buchs PA, Muller D (1991) A simple method for organotypic cultures of nervous tissue. J Neurosci Methods 37:173-182.

Zhu P, Aller MI, Baron U, Cambridge S, Bausen M, Herb J, Sawinski J, Cetin A, Osten P, Nelson ML, Kügler S, Seeburg PH, Sprengel R, Hasan MT (2007) Silencing and unsilencing of tetracycline-controlled genes in neurons. PLoS ONE 2:e533.

Zolotukhin S, Byrne BJ, Mason E, Zolotukhin I, Potter M, Chesnut K, Summerford C, Samulski RJ, Muzyczka N (1999) Recombinant adeno-associated virus purification using novel methods improves infectious titer and yield. Gene Ther 6:973-985. 